This article was downloaded by: [National Taiwan University]

On: 16 December 2008

Access details: Access Details: [subscription number 788846425]

Publisher Taylor \& Francis

Informa Ltd Registered in England and Wales Registered Number: 1072954 Registered office: Mortimer House, 37-41 Mortimer Street, London W1T 3JH, UK

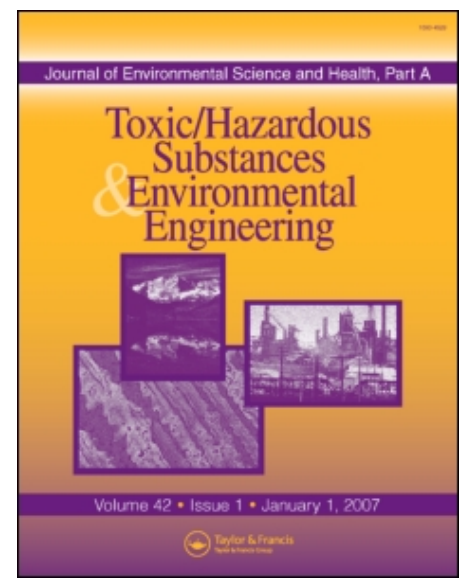

Journal of Environmental Science and Health, Part A

Publication details, including instructions for authors and subscription information:

http://www.informaworld.com/smpp/title content=t713597268

\title{
Interpolating Precipitation and its Relation to Runoff and Non-Point Source
}

Pollution

Chia-Ling Chang a; Shang-Lien Lo a; Shaw-L Yu ${ }^{\mathrm{b}}$

a Graduate Institute of Environmental Engineering, National Taiwan University, Taipei 106, Taiwan ${ }^{b}$

Department of Civil Engineering, University of Virginia, Charlottesville, Virginia, USA

Online Publication Date: 01 October 2005

To cite this Article Chang, Chia-Ling, Lo, Shang-Lien and Yu, Shaw-L(2005)'Interpolating Precipitation and its Relation to Runoff and Non-Point Source Pollution',Journal of Environmental Science and Health, Part A,40:10,1963 - 1973

To link to this Article: DOI: $10.1080 / 10934520500184673$

URL: http://dx.doi.org/10.1080/10934520500184673

PLEASE SCROLL DOWN FOR ARTICLE

\footnotetext{
Full terms and conditions of use: http://www.informaworld.com/terms-and-conditions-of-access.pdf

This article may be used for research, teaching and private study purposes. Any substantial or systematic reproduction, re-distribution, re-selling, loan or sub-licensing, systematic supply or distribution in any form to anyone is expressly forbidden.

The publisher does not give any warranty express or implied or make any representation that the contents will be complete or accurate or up to date. The accuracy of any instructions, formulae and drug doses should be independently verified with primary sources. The publisher shall not be liable for any loss, actions, claims, proceedings, demand or costs or damages whatsoever or howsoever caused arising directly or indirectly in connection with or arising out of the use of this material.
} 


\title{
Interpolating Precipitation and its Relation to Runoff and Non-Point Source Pollution
}

\author{
Chia-Ling Chang, ${ }^{1}$ Shang-Lien Lo, ${ }^{1}$ and Shaw-L YU' \\ ${ }^{1}$ Graduate Institute of Environmental Engineering, National Taiwan University, \\ Taipei 106, Taiwan \\ ${ }^{2}$ Department of Civil Engineering, University of Virginia, Charlottesville, Virginia, USA
}

When rainfall spatially varies, complete rainfall data for each region with different rainfall characteristics are very important. Numerous interpolation methods have been developed for estimating unknown spatial characteristics. However, no interpolation method is suitable for all circumstances. In this study, several methods, including the arithmetic average method, the Thiessen Polygons method, the traditional inverse distance method, and the modified inverse distance method, were used to interpolate precipitation. The modified inverse distance method considers not only horizontal distances but also differences between the elevations of the region with no rainfall records and of its surrounding rainfall stations. The results show that when the spatial variation of rainfall is strong, choosing a suitable interpolation method is very important. If the rainfall is uniform, the precipitation estimated using any interpolation method would be quite close to the actual precipitation. When rainfall is heavy in locations with high elevation, the rainfall changes with the elevation. In this situation, the modified inverse distance method is much more effective than any other method discussed herein for estimating the rainfall input for WinVAST to estimate runoff and non-point source pollution (NPSP). When the spatial variation of rainfall is random, regardless of the interpolation method used to yield rainfall input, the estimation errors of runoff and NPSP are large. Moreover, the relationship between the relative error of the predicted runoff and predicted pollutant loading of SS is high. However, the pollutant concentration is affected by both runoff and pollutant export, so the relationship between the relative error of the predicted runoff and the predicted pollutant concentration of SS may be unstable.

Key Words: Non-point source pollution (NPSP); Precipitation interpolation; Runoff; Watershed management; WinVAST.

Address correspondence to Chia-Ling Chang, Graduate Institute of Environmental Engineering, National Taiwan University, No. 71, Chou-Shan Road, Taipei 106, Taiwan; E-mail: f89541201@ntu.edu.tw 


\section{INTRODUCTION}

The sustainable use of water resources and watershed management are significant issues that have been discussed in many works. Some hydrology and water quality models have been developed to predict how much rainfall is transferred to water resources. The input parameters and data required for such models usually exhibit spatial variation even in a small watershed. The accuracy of the input data for the models can seriously influence the modeling results. Therefore, the absence of spatial varying information is a large obstacle to the development of models. In particular, an incomplete understanding of the spatial variation of rainfall can result in much uncertainty in the calculations of runoff and water quality, ${ }^{[1]}$ even though small-scale spatial variations of rainfall can cause large variation of the simulated runoff. ${ }^{[2]}$ The uncertainty in modeling associated with the use of the rainfall records obtained using only one gauge may be serious and cannot be ignored. ${ }^{[3]}$ Accordingly, some model frameworks, through the design of sub-basin divisions or grid inputs, allow users to input information separately for each partition to represent the spatial variation in a watershed. However, gauging stations, incorporating rainfall gauges and flow gauges, for example, cannot be established all over a watershed, so limited monitored data must be used to interpolate unknown information to describe the actual condition in a watershed.

Numerous interpolation methods for estimating rainfall are available, but no method is suitable for every circumstance. ${ }^{[4]}$ Rainfall characteristics and watershed conditions can affect the choice of interpolation method. Interpolation errors can have serious effects, especially on spatially distributed models. ${ }^{[5]}$ The optimal interpolation method, the Kriging method, and the weighted mean method, among others, are commonly used to estimate precipitation and analyze the spatial variation of rainfall. Certainly, if detailed data have been obtained, interpolation is simpler. However, if the monitored data are too few, then interpolation methods that do not need complicated data must be chosen. Among the commonly used interpolation methods mentioned above, the optimal interpolation method and the Kriging method, are very limited, because they depend on complex and complete data. ${ }^{[6,7]}$ If the rainfall gauges are inadequate, these methods yield great uncertainty. On the contrary, the weighted mean method is more flexible, because the weightings of data from surrounding rainfall stations can be adjusted.

This article discusses several weighted mean methods for interpolating rainfall, including the arithmetic average method, the Thiessen Polygons method, the traditional inverse distance method, and the modified inverse distance method. The objective of this study was to compare the runoff and non-point source pollution (NPSP) simulation results for various rainfall inputs obtained using these selected interpolation methods. 


\section{METHODS}

\section{Weighted Mean Methods}

Predicting the watershed response to a given rainfall event often requires a knowledge of the average precipitation in a watershed over a specified duration. ${ }^{[8]}$ Rainfall can vary greatly over a large geographical area. ${ }^{[9]}$ Three methods are commonly used to estimate average precipitation over an area: arithmetic average, isohyetal, and Thiessen Polygons methods. ${ }^{[8,9]}$ In this study, the arithmetic average and Thiessen Polygons methods were used to interpolate unknown precipitation and estimate the average precipitation in an area. Additionally, the inverse distance method is useful for estimating precipitation. The traditional and modified inverse distance methods, of which the latter considers the effects of both horizontal distances and the difference between the elevations of two locations, are discussed.

All these methods belong to the weighted mean methods for interpolating, because the unknown precipitation and average precipitation can be calculated after deciding the weighting factors for each rainfall gauge. The basic calculation is given by

$$
P_{p}=\sum_{i=1}^{N}\left(W_{p i} \cdot P_{i}\right)
$$

where $P_{p}$ is the average precipitation in topographic basin $p, P_{i}$ is the precipitation at rainfall gauge $i$ within or surrounding this area, $W_{p i}$ is the weighting factor for rainfall gauge $i$, and $N$ is the number of rainfall gauging station within or surrounding this area, that is, the number of available and considered rainfall gauges.

The arithmetic average method is a simple approach that uses an arithmetic mean of point rainfalls obtained from available rainfall gauges. Restated, all the available gauging stations, within or surrounding the study area, have the same weighting factors. This method is effective if the gauges are uniformly distributed and individual variations are not far from the mean rainfall. However, it may be unsatisfactory over large areas in which the rainfall distribution is variable. ${ }^{[8,9]}$ It is calculated by

$$
\begin{aligned}
W_{p i} & =1 / N \\
P_{p} & =\sum_{i=0}^{N} W_{p i} P_{i}=\sum_{i=1}^{N} P_{i} / N
\end{aligned}
$$

The Thiessen Polygons method can also be used to calculate the average precipitation. This method adjusts for the nonuniform distribution of the locations of the gauging stations by attempting to determine the area of influence. The ratio of the area of influence of a station in the topographic basin to the total 
area of the topographic basin is a weighting factor to be applied in calculating the average value. Connecting lines are drawn between each pair of rainfall gauges. Then, perpendicular bisectors are drawn to form polygons around each gauge. The area of each polygon is determined and is called the control area. A weighted area is determined by

$$
\begin{aligned}
W_{p i} & =A_{i} / A \\
P_{p} & =\sum_{i=0}^{N} W_{p i} P_{i}=\sum_{i=1}^{N} \frac{A_{i}}{A} P_{i}
\end{aligned}
$$

where $A_{i}$ is the area of polygon $\mathrm{i}$ within the study area and $A$ is the total area.

The inverse distance method is very popular for interpolating precipitation. In this method, the horizontal distances between the areas with unknown precipitation and all the rainfall gauges determine the weighting factors. ${ }^{[10]}$ Our previous work found that adjusting the order of the distances in the inverse distance method can improve the accuracy for estimating precipitation. ${ }^{[11]}$ The weighting factor is defined as

$$
\begin{aligned}
W_{p i} & =\frac{\left(\frac{1}{d_{p i}^{m}}\right)}{\left(\sum_{i=1}^{N} \frac{1}{d_{p i}^{m}}\right)} \\
P_{p} & =\sum_{i=0}^{N} W_{p i} P_{i}=\sum_{i=0}^{N} \frac{\left(\frac{1}{d_{p i}^{m}}\right)}{\left(\sum_{i=0}^{n} \frac{1}{d_{p i}^{m}}\right)} P_{i}
\end{aligned}
$$

where $d_{p i}$ is the horizontal distance between the center of area $p$ in which the precipitation is unknown and rainfall gauge $i$ and $m$ is the order of horizontal distances. Similarly, after determining the weighting factors, the average precipitation can be calculated. In this study, the order of horizontal distances was given by 2 , which is the most general value for the value of $m$.

The modified inverse distance method considers the effect of not only horizontal distances but also the difference between the elevation of a location without rainfall records and the locations of surrounding rainfall stations. The weighting factors for each neighboring rainfall gauge are determined by the effect of the horizontal distances and the differences between the elevations. The effects are combined by multiplication. The basic calculation is listed as 
follows:

$$
\begin{aligned}
W d_{p i}= & \frac{\left(\frac{1}{d_{p i}^{m}}\right)}{\left(\sum_{i=1}^{N} \frac{1}{d_{p i}^{m}}\right)} \\
W h_{p i}= & \frac{\left(\frac{1}{h_{p i}^{n}}\right)}{\left(\sum_{i=1}^{N} \frac{1}{h_{p i}^{n}}\right)} \\
W_{p i}= & W d_{p i} \cdot W h_{p i}=\frac{\left(\frac{1}{d_{p i}^{m}}\right)}{\left(\sum_{i=1}^{N} \frac{1}{d_{p i}^{m}}\right)} \cdot \frac{\left(\frac{1}{h_{p i}^{n}}\right)}{\left(\sum_{i=1}^{N} \frac{1}{h_{p i}^{n}}\right)} \\
P_{p}= & \sum_{i=0}^{N} W_{p i} P_{i}=\sum_{i=0}^{N} W d_{p i} W h_{p i} P_{i}=\sum_{i=0}^{N} \frac{\left(\frac{1}{d_{p i}^{m}}\right)}{\left(\sum_{i=0}^{n} \frac{1}{d_{p i}^{m}}\right)} \frac{\left(\frac{1}{h_{p i}^{m}}\right)}{\left(\sum_{i=0}^{n} \frac{1}{h_{p i}^{m}}\right)} P_{i}
\end{aligned}
$$

where $h_{p i}$ is the elevation difference between the center of area $p$ in which the precipitation is unknown and rainfall gauge $i$ and $n$ is the order of elevation differences. The orders of horizontal distances and elevation differences are adjustable. Genetic algorithm was used to minimize the difference between estimated precipitation and actual precipitation to get optimal values for $m$ and $n$.

\section{Model for Runoff and NPSP Simulation}

Runoff is important hydrological information used in efficiently providing the lack of water or heavy flood. If runoff increases extremely rapidly, water in streams may not be able to be driven out. In that situation, the rainfall is not transferred to a water resource, so such a circumstances may detrimentally affect people's health and wealth. Also, the transportation of water over ground removes material such as soil and pollutants. If the water that carries soil and pollutants flows into a reservoir, it affects the quality of the water in that reservoir, causing, for example, eutrophication and silting, which have recently become critical problems.

In this study, the WinVAST model was applied to predict runoff. The WinVAST is a collection of computer programs developed for simulating 
stormwater runoff, NPSP, and pollutant transportation. It is an event-oriented model that can be applied to multiple catchment basins. WinVAST combines widely used techniques, which involve calculating rainfall abstractions, generating overland flow hygrographs, estimating flood routing from upstream subbasins through downstream sub-basins, computing NPSP wash-off from subbasins, simulating routing pollutants, and predicting the condition through selected best management practices. ${ }^{[12,13]}$ WinVAST treats multicatchment basins as a tree-view structure, so a complex representation of the entire catchment basin can be easily generated.

\section{Case Study}

Synthetic data are useful in overcoming the limitations on measured data. ${ }^{[14,15]}$ Figure 1 presents the synthetic case area designed in this work. The case area has 10 sub-basins, each of which has an area of $2 \mathrm{~km}^{2}$. The length of the main stream in each sub-basin is $2000 \mathrm{~m}$. All the land is used as forest, and the average slope is 5\%. The curve number for the forest is 70 . The general pollutant loading of SS in forest is $0.15 \mathrm{~kg} / \mathrm{ha} /$ day. Four rainfall events with different distributions were designed. Rainfall event "a" is uniform rainfall. Spatial variation applies to rainfall events "b," "c," and "d." The spatial variation of rainfall event "b" changes with the elevation. Restated, a higher elevation is associated with greater precipitation. The heavy precipitation of rainfall event "c" is mainly in the downstream subbasins. Moreover, the spatial

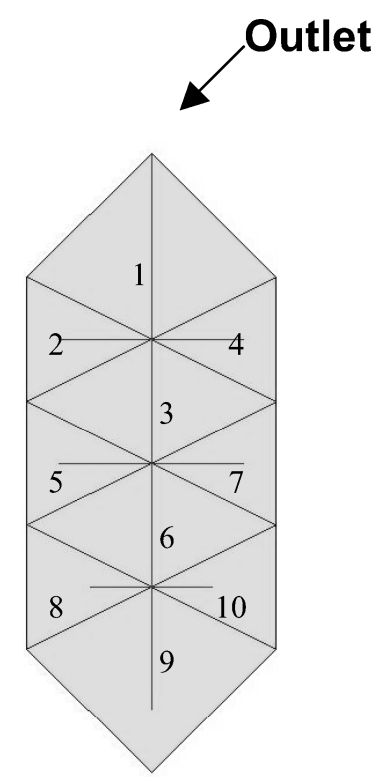

Figure 1: Synthetic case area with 10 sub-basins. 
variation of rainfall event " $\mathrm{d}$ " is random. Restated, heavy rainfall is not regional and does not vary with the topography.

All the rainfall data in each sub-basin represent the rainfall characteristics in that region. Based on this assumption, if the rainfall records are complete, then the predicted runoff and pollutant export can be regarded as the actual output. Rainfall data were assumed to be absent for sub-basins $2,3,5,6,7$, and 10 , so the rainfall records for sub-basins $1,4,8$, and 9 were used to interpolate the unknown precipitation.

\section{RESULTS AND DISCUSSION}

Various rainfall events, including uniform rainfall and spatially varying rainfall, are discussed herein. Figures 2, 3, and 4 presents the hydrographs, the pollutant concentrations of SS, and the pollutant loadings of SS at the outlet, respectively. When the rainfall distribution is uniform, such as in the case of
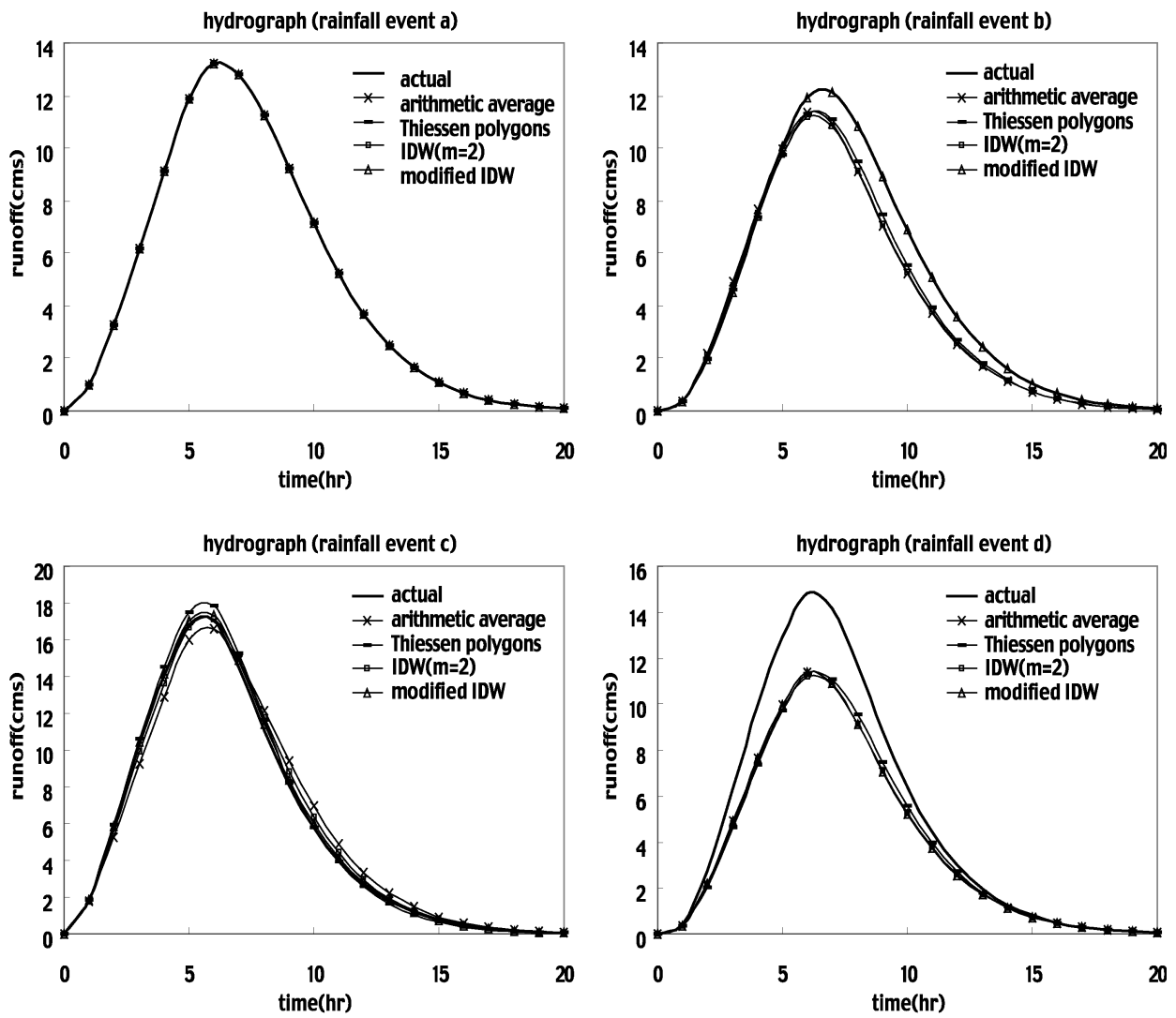

Figure 2: Hydrographs at the outlet in these four rainfall events through different rainfall input estimated by several interpolation methods. 

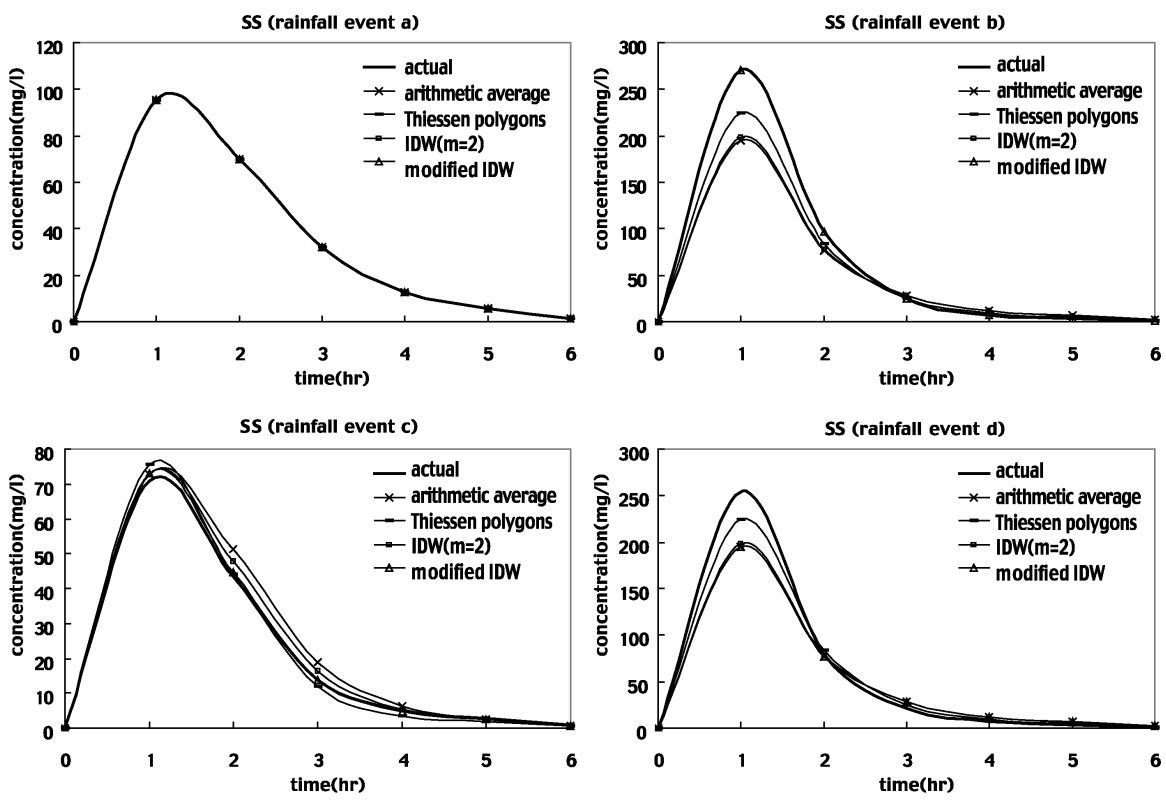

Figure 3: Profiles of the pollutant concentration at the outlet in these four rainfall events through different rainfall input estimated by several interpolation methods.
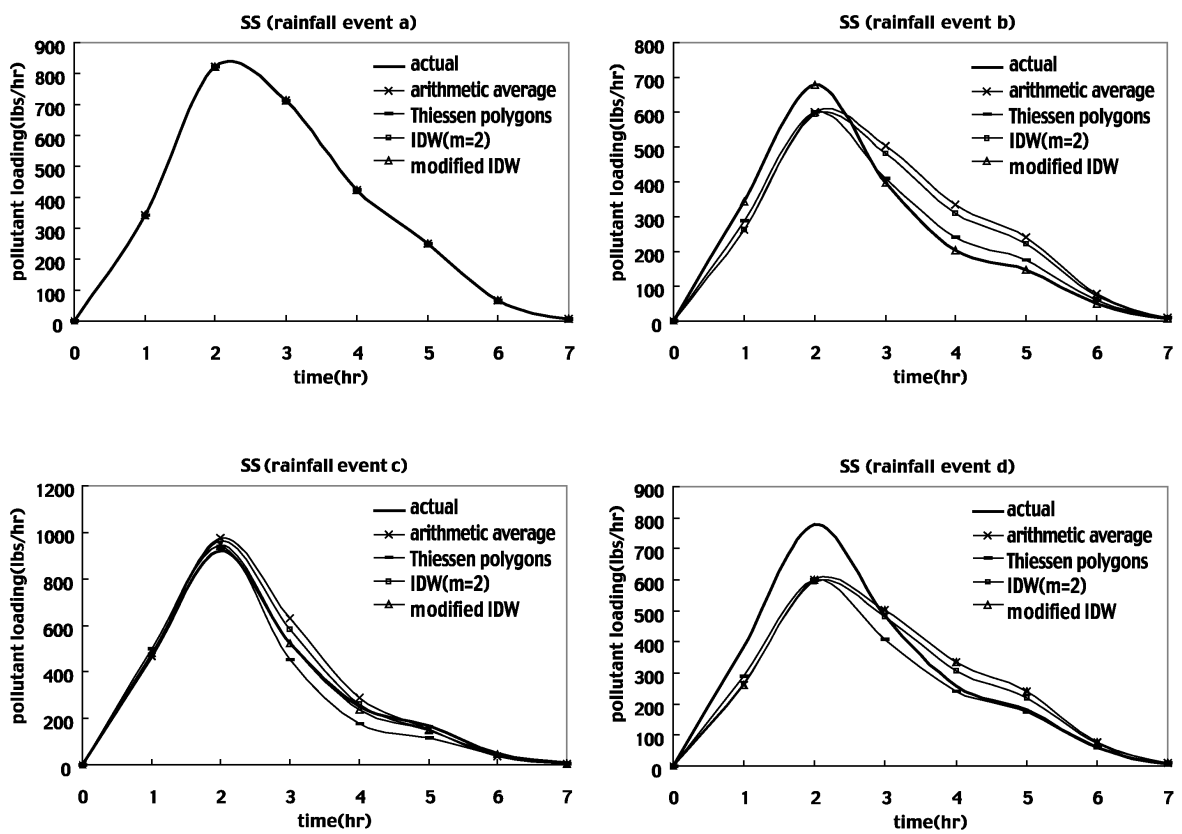

Figure 4: Profiles of the pollutant loading at the outlet in these four rainfall events through different rainfall input estimated by several interpolation methods. 
rainfall event "a" stated above, the method used for interpolating unknown precipitation does not noticeably affect the estimated precipitation. Therefore, the predicted runoff and the pollutant export of SS are the same using the estimated precipitation obtained by any of these interpolation methods. When the rainfall varies spatially, selecting a suitable method for interpolating precipitation is very important.

Three spatially varying rainfalls-one that spatially varies with topography, one regionally concentrated, and one varying randomly, rainfall events " $b$," "c," and "d," respectively_-were specified. When the spatial variation of the rainfall is strongly related to the elevation, as in the case of rainfall event "b," the precipitation estimated using the modified inverse distance method is closer to the actual rainfall than in other cases, so the predicted runoff and pollutant export are more accurate, because the modified inverse distance method considers not only horizontal distances but also the differences between the elevations of the location without rainfall records and the locations of the surrounding rainfall gauges.

When the heavy rainfall is concentrated in some regions but these regions are not all at high elevation, as for rainfall event "c," the error in the predicted runoff and pollutant export can be approximated using the interpolated

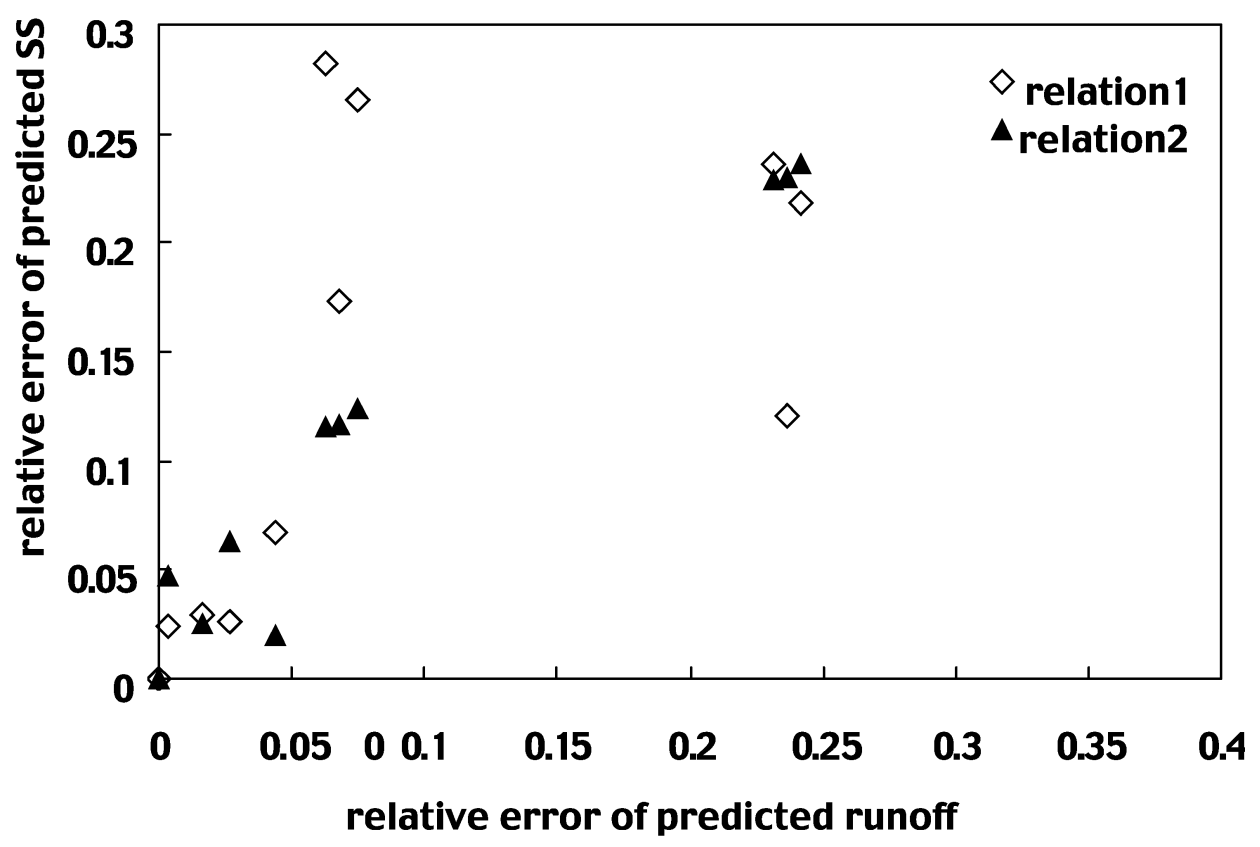

Figure 5: Relation between estimation errors of predicted runoff and estimation errors of predicted SS export. Relation 1, the relation between relative error of predicted runoff and relative error of predicted pollutant concentration of SS; relation 2, the relation between relative error of predicted runoff and relative error of predicted pollutant loading of SS. 
precipitation determined by any of the selected interpolation methods discussed herein. Moreover, when the rainfall is randomly distribution, as in rainfall event "d," the spatial variation of the rainfall does not vary with any visible effect. Under this kind of rainfall distribution, regardless of the interpolation method used for estimating the precipitation, the error in the estimate of precipitation is cannot easily be controlled or reduced. Therefore, the errors in the estimates of the predicted runoff and pollutant export are also large.

The dilution substantially varies the concentration of the pollutant, potentially affecting the body of water. Therefore, the relationship between the relative error of the predicted runoff and that of the predicted pollutant loading of SS, which is defined as relation 2 in Figure 5, is much stronger than that between the relative error of the predicted runoff and the relative error of the predicted pollutant concentration of SS, which is defined as relation 1 in Figure 5. The $R$-squared value for relation 2 is about 0.93 ; that of relation 1 is only 0.36 . The curves of the hydrographs are similar to the profiles of the pollutant loading at the outlet, but the trends of the pollutant concentration are unstable.

\section{CONCLUSION}

The spatial variation of the rainfall in a watershed is critical information for predicting runoff and NPSP. The precipitation must be interpolated when the rainfall records are incomplete. The choice of the interpolation method depends on the spatial distribution of the rainfall. The results are as follows.

1. If the rainfall is uniform, then the precipitations estimated by the interpolation methods selected herein are similar. However, when the spatial variation of the rainfall is large, choosing a suitable interpolation method for estimating unknown precipitation is very important.

2 . When the spatial variation changes with the topography, the modified inverse distance method more accurately estimates precipitation than does the arithmetic average method, the Thiessen Polygons method, or the inverse square distance method, perhaps because the former considers the effect of the horizontal distances and the differences between the elevations of each pair of locations.

3. When heavy rainfall is regionally concentrated, the predicted runoff and pollutant export are approximate, regardless of the rainfall input estimated by any of the interpolation methods discussed herein.

4. Regardless of which interpolation method is used to obtain the complete rainfall input, the estimation error cannot be efficiently reduced when the rainfall distribution is random. 
5. Dilution causes the relationship between the relative error of the predicted runoff and that of the pollutant loading of SS to exceed greatly that between the relative error of the predicted runoff and that of the pollutant concentration of SS.

\section{REFERENCES}

1. Vicente, L.L. On the effect of uncertainty in spatial distribution of rainfall on catchment modeling. Catena 1996, 28, 107-119.

2. Faures, J.M.; Goodrich, D.C.; Davis, A.W.; Soroosh, S. Impact of small-scale spatial variability on runoff modeling. J. Hydrol. 1995, 173, 309-326.

3. Chaubey, I.; Haan, C.T.; Grunwald, S.; Salisbury, J.M. Uncertainty in the model parameters due to spatial variability of rainfall. J. Hydrol. 1999, 220, 48-61.

4. Nalder, I.A.; Wein, R.W. Spatial interpolation of climatic normals: test of a new method in the Canadian boreal forest. Agric. For. Meteorol. 1998, 92, 211-225.

5. Donald, L.P.; Danny, G.M. Spatial uncertainty analysis: propagation of interpolation errors in spatially distributed models. Ecol. Model. 1996, 91, 213-229.

6. Tabios, G.O.; Salas, J.D. A comparative analysis of techniques for spatial interpolation of precipitation. Water Resour. Res. 1985, 21, 365-380.

7. Dirks, K.N.; Hay, J.E.; Stow, C.D.; Harris, D. High-resolution studies of rainfall on Norfolk island, Part I. The spatial variability of rainfall. J. Hydrol. 1998, 208, 163-186.

8. Bedient, P.B.; Huber, W.C. Hydrology and floodplain analysis, Prentice-Hall: Upper Saddle River, NJ, 2002, 34-35.

9. Wanielista, M.; Kersten, R.; Eaglin, R. Hydrology-water quantity and quality control; John Wiley \& Sons: New york; 1997, 91-96.

10. Bartier, P.M.; Keller, C.P. Multivariate interpolation to incorporate thematic surface data using inverse distance weighting (IDW). Comput. Geosci. 1996, 22, 795-799.

11. Chang, C.L.; Lo, S.L.; Yu, S.L.; Hu, C.Y. Combining variable order inverse distance method and genetic algorithm to precipitation interpolation in Fei-tsui Reservoir Watershed. Proceedings of the IWA Asia-Pacific Regional Conference, Tailand, Oct. 20-22, 2003.

12. Tisdale, T.S.; Kaighn, R.J.; Yu, S.L. The Virginia storm (VAST) model for stormwater management. User's guide, version 6.0. University of Virginia: Charlottesville, Virginia; 1996.

13. Yu, S.L.; Stanford, R.L.; Zhai, Y.Y. Virginia stormwater model for windows. User's manual, version 1.0. University of Virginia: Charlottesville, Virginia; 2003.

14. Hromadka, T.V. A rainfall-runoff probabilistic simulation program. 1. Synthetic data generation. Environ. Softw. 1996, 11, 235-242.

15. Hromadka, T.V. A rainfall-runoff probabilistic simulation program. 2. Synthetic data analysis, Environ. Softw. 1996, 11, 243-249. 